\title{
ASPECTOS DA RELIGIOSIDADE BRASILEIRA HIPERMODERNA EM TEMPOS DE PANDEMIA
}

\author{
Sérgio Luís Tavares ${ }^{1}$
}

\section{Resumo}

Este artigo apresenta aspectos da religiosidade brasileira no cenário da pandemia por Coronavírus, à luz da análise filosófica feita por Gilles Lipovetsky e Sébastien Charles na obra Os Tempos Hipermodernos, que relaciona as características da Hipermodernidade com comportamentos, inclusive religiosos. Faz-se uma interface entre os "exageros" da Hipermodernidade, com o caráter plural, sincrético e "democrático" da religiosidade brasileira. A pesquisa procura demonstrar ainda que os efeitos da pandemia vem sendo diferenciados entre as religiosidades brasileiras.

Palavras-chave: Religiosidade; Hipermodernidade; Pandemia; Brasil; Comportamento.

\section{ASPECTS OF HYPERERMODERN BRAZILIAN RELIGIOSITY IN PANDEMIC TIMES}

\begin{abstract}
This article presents aspects of Brazilian religiosity in the context of the Coronavirus pandemic, in the light of the philosophical analysis made by Gilles Lipovetsky and Sébastien Charles in the work Os Hipermodernos Tempos, which links the characteristics of Hypermodernity with behaviors, including religious ones. An interface is made between the "exaggerations" of Hypermodernity, with the plural, syncretic and "democratic" character of Brazilian religiosity. The research also seeks to demonstrate that the effects of the pandemic have been differentiated among Brazilian religiosities.
\end{abstract}

Keywords: Religiosity; Hypermodernity; Pandemic; Brazil; Behavior.

\section{INTRODUÇÃO}

Mostra-se sempre muito desafiador tratar da religiosidade brasileira, inicialmente por se ter em mente que a nossa sociedade se apresenta como um enigmático mosaico, repleto de

\footnotetext{
${ }^{1}$ Mestre em Direito Público e Evolução Social pela Universidade Estácio de Sá (UNESA). Especialista em Direito Público pela Universidade Estácio de Sá (UNESA). Especialista em Direito e Estado pela Universidade Cândido Mendes (UCAM). Graduado em Teologia pela Faculdade de Ciências, Educação e Teologia do Norte do Brasil (FACETEN). Pesquisador do Grupo de Pesquisa Direitos Humanos e Transformação Social da Universidade Federal do Estado do Rio de Janeiro (UNIRIO), coordenado pela Professora Pós-Dra. Edna Raquel R. S. Hogemann. Escritor. Professor. Advogado. Lattes: http://lattes.cnpq.br/6831742185571886. Email: sergio_tavares_2004@yahoo.com.br. ID ORCID https://orcid.org/0000-0001-9094-5574
} 
peças de encaixe, provenientes das várias culturas que contribuíram para a composição desse conjunto.

Peças que nem sempre estão bem acopladas umas às outras, seja porque foram mal forjadas, ou porque foram sendo deformadas por ações ou omissões patrocinadas por indivíduos e grupos que se colocaram a violar a liberdade de consciência e de culto de outros que quedaram como oprimidos.

Entretanto, o desafio não se limita ao enfrentamento da grandiosidade e complexidade da história e dos desdobramentos sociológicos das religiões no Brasil. Continua ao se cotejar os principais perfis da religiosidade brasileira com determinadas deformidades desse tempo, denominado "hipermoderno" por Gilles Lipovetsky e Sébastien Charles na obra Os Tempos Hipermodernos, publicada em 2004.

Tais variações hipermodernas revelam os exageros que se fazem presentes nas relações humanas, o que, evidentemente, atinge os arraiás religiosos brasileiros, sem distinções se essa religião afetada outrora era a do europeu colonizador, ou aquela desenvolvida pelas minorias oprimidas.

Os tempos hipermodernos apontam para uma religiosidade individualizada, uma lógica da moda e do consumo, metas de prazer, satisfação e sucesso e práticas mercadológicas, como disputa de clientela, publicidade e uso de internet e mídias sociais.

Logicamente, quando se trata de um país plural em sua religiosidade, deve-se ter em conta que os tentáculos hipermodernos não conseguiram atingir todas as formas de religiões no Brasil, até mesmo pelas peculiaridades e propósitos de cada qual.

Mesmo assim, a leitura feita por Lipovetsky e Charles merece o seu devido destaque, como instrumento de aferição para religiosidades como diversas denominações do Protestantismo Pentecostal e Neopentecostal brasileiro.

$\mathrm{O}$ artigo também explana sobre aspectos gerais dos saberes e fazeres do povo brasileiro, que inclui um incontestável espírito conciliador, provavelmente formatado pelas recorrentes experiências sincréticas, oriunda do "encontro das raças", que se deu em terra brasilis.

A pluralidade cultural do povo brasileiro e essa "democracia" religiosa, é bem verdade, vê-se, vez por outra, ameaçada por episódios de intolerância religiosa e práticas fundamentalistas, que propagam ódio, perseguição, discriminação e preconceitos de diversas ordens. 
Por fim, o artigo situa a abordagem da religiosidade brasileira, sob as lentes da hipermodernidade, conjugadas com os percalços do presente momento em que as coletividades humanas se deparam com a ameaça constante de doença e morte, propagada pelo novo Coronavírus.

O próprio conceito de "religião" é questionado pelo artigo, considerando que a pandemia vem demonstrando que as religiosidades reagem de formas diferenciadas, não apenas pela opção de seus líderes e seguidores, como também pelas próprias características litúrgicas e dogmáticas.

Será exposto que as chamadas religiões culturalistas brasileiras, em regra, comportaram-se de forma diferenciada em relação às religiões prosélicas, quanto à questão da dicotomia entre o confinamento e os ajuntamentos religiosos.

A metodologia empregada é a análise bibliográfica, tendo a obra de Lipovetsky e Charles como referencial, parametrizada por práticas sociais, especialmente religiosas, observadas pelo autor, na dimensão de uma pesquisa empírica, que aponta para o presente tempo vivido, quando a pandemia pelo Coronavírus e as medidas de confinamento e restrições sociais interferiram nas práticas religiosas.

\section{ASPECTOS GERAIS DA RELIGIOSIDADE BRASILEIRA CONTEMPORÂNEA}

Tratar a religiosidade brasileira, ao menos de forma panorâmica e sob as lentes de uma observação contemporânea, implica realçar traços muito evidenciados e típicos de nossa população, dentre os quais uma expressiva fusão litúrgica e de outros comportamentos religiosos, decorrente do encontro, sinergia e interação de diferentes culturas e demais traços sociais.

Tende-se a reduzir tal sincretismo a três grandes raízes culturais: a branca europeia, historicamente como a religião do dominador, e mais duas religiosidades de comunidades que foram subjugadas, ou seja, a indígena e a africana. No entanto, outros povos e respectivas culturas participaram e ainda participam desse grande mosaico religioso no Brasil.

A palavra "sincretismo" que, outrora já carregou um sentido depreciativo, como sendo uma conciliação malfeita entre diferentes visões de mundo, passou a identificar, no campo das religiões, fenômenos de sobreposição ou fusão de crenças de origens diversas. 
No caso brasileiro, não é erro afirmar que o pluralismo e o sincretismo religiosos são marcantes ao formar uma verdadeira "feira mística", onde a mistura de tradições e de crenças diferentes gera continuamente novas formas religiosas e onde essa espiritualidade sincrética ultrapassa os parâmetros das religiões institucionalizadas, de modo a construir uma identidade cultural de nosso povo.

Nesse sentido, Pfeffer elucida:

No caos de desejos, emoções e ideias que compõem a sociedade brasileira, a harmonia religiosa brasileira - sua coordenação intuitiva eficiente - conseguiu evitar, ao menos na maioria das vezes, os rumos do fanatismo e do excesso de racionalidade, dando contorno à nossa identidade. A mestiçagem cultural foi a marca do Brasil desde a descoberta e o fator fundamental constitutivo de sua identidade cultural. [...]

O sincretismo no Brasil tornou-se agente da civilização. Somos um país híbrido, o que nos dá identidade e o que pode ser nossa contribuição específica para o mundo. Aprendemos a fundir códigos de uma maneira alegre e festiva, o que gerou uma profunda confraternização de valores e sentimentos das culturas religiosas que compuseram o país (PFEFFER, 2013, p. 118-119).

O sincretismo religioso, dessa forma, despontou como um fator de construção da identidade cultural do povo brasileiro, por meio de processos dinâmicos pelos quais indivíduos e grupos sociais passaram a buscar respostas para questões de foro íntimo, através da transcendência e do acesso a tradições, comportamentos e costumes, desencadeando no grande pluralismo religioso atual.

Não obstante os casos de intolerância religiosa e condutas fundamentalistas observadas com incômoda frequência no seio da sociedade brasileira de hoje, o fato é que a diversidade cultural e, provavelmente, o próprio estilo predominante dos brasileiros, alinhavaram um mosaico religioso substancialmente "democrático"

A esse respeito, o antropólogo Roberto da Matta assim discorreu:

O ponto é utilizar consistentemente a descoberta de que a sociedade brasileira é relacional. Um sistema onde o básico, o valor fundamental, é relacionar, juntar, confundir, conciliar. Ficar no meio, descobrir a mediação e estabelecer a gradação, incluir (jamais excluir). Sintetizar modelos e posições parece constituir um aspecto central da ideologia dominante brasileira (DAMATTA, 1987, p. 117).

Ainda acerca do sincretismo religioso, vê-se que o mesmo funcionou como um verdadeiro mecanismo de resistência por parte dos grupos que comungavam da cultura dominada e oprimida, como foi o caso dos indígenas e principalmente dos africanos e descendentes que foram escravizados no Brasil. 
O sincretismo religioso, enquanto fator de resistência, teve o importante papel de mascarar os cultos africanos e ameríndios diante das proibições e punições que poderiam ser impostas pelo poder político do colonialista e depois governante português.

Além dessa função de camuflar a religiosidade dessas minorias, o sincretismo auxiliou no empoderamento simbólico das divindades africanas e ameríndias, pela justaposição delas com as divindades católicas, até então detentoras de maior poder simbólico no seio da cultura brasileira.

Apesar das inúmeras possibilidades de sincretismos religiosos no Brasil, ao considerarmos as três principais etnias que compuseram a nacionalidade brasileira e seus traços religiosos dominantes, podemos identificar três principais tipos de sincretismos em nosso país: o católico-indígena, o indígena-africano e o afro-católico.

Todavia, quando o assunto é o cenário da religiosidade brasileira da atualidade, também não se pode ignorar os processos de privatização das experiências religiosas, com a ocupação de espaços públicos pelos religiosos e respectivas instituições, tal qual se deu com a emergência de partidos confessionais.

Pode-se indagar se a ocupação dos espaços políticos por pessoas manifesta e declaradamente religiosas, não poderia representar, em última análise, um esboço de "confessionalizar" setores das instituições brasileiras e ameaçar, com isso, o perfil laico anunciado e pretendido pela Constituição brasileira de 1988.

Outra reflexão é se, no Brasil, existem verdadeiramente "partidos confessionais", ao menos como representação da apropriação do rótulo "religioso" por aqueles que estão no exercício ou na pretensão do desempenho da atividade política, ou se isso seria uma mera estratégia de captação de votos dos eleitores com tal perfil.

$\mathrm{Na}$ história do Brasil, esses grupos político-partidários já receberam diversas denominações para indicar suas bases doutrinárias, relacionadas aos fundamentos de alguma religião institucionalizada, como partidos "católicos", "democráticos-cristãos", "religiosos", “protestantes” (MAYEUR, 1986, p. 890-898).

Avaliando mais detidamente o cenário brasileiro, Santos (2015, p. 205) afirma que "Religião e política sempre caminharam lado a lado no processo histórico. Ora houve separação, ora houve fusão entre ambas". Além disso, a realidade de um eleitorado 
predominantemente religioso e, ao mesmo tempo, repleto de carências materiais, desperta o interesse eleitoral e a exploração da questão religiosa em meio aos discursos políticos.

A análise da presença pública da religião é um tema absolutamente relacionado à laicidade do Estado, uma vez que investiga a constituição e manutenção desses modos de presença do elemento religioso no espaço público e como se dão esses diálogos entre os coletivos religiosos e outras instituições como o próprio Estado.

Em outras palavras, refletir sobre a presença pública da religião é mensurar o quanto um Estado laico, como o brasileiro, por conta dessa laicidade, legitima a presença do religioso no espaço público.

No caso do Brasil, Giumbelli (2008) preferiu fazer essa análise a partir das principais religiões brasileiras, numa evolução histórica:

\begin{abstract}
No caso da Igreja Católica, isso ocorreu inicialmente por meio de uma aliança simbólica e material e com a ajuda de um regime jurídico de baixo controle estatal. No caso do espiritismo, ocorreu em meio a uma batalha pela legitimidade de práticas com algum sentido terapêutico. No caso dos cultos afros, envolveu a aceitação de um argumento culturalista. Partindo do delineamento histórico de diferentes modalidades de reconhecimento, busca-se a caracterização do que ocorre atualmente, considerando a presença dos evangélicos no espaço público (GIUMBELLI, 2008, p. 101).
\end{abstract}

E nessa investigação, conforme DaMatta (1986), vê-se que a falta de um tratamento igual e uniforme para todos os sistemas religiosos inviabilizou o pleno reconhecimento dos direitos de certas matrizes religiosas, promovendo o acesso particularizado e desigual de determinadas religiões ao espaço público no Brasil. É como se o Estado brasileiro, ao longo dos tempos, fosse legitimando mais uma ou outra religião em detrimento das demais, o que, em tese, depõe contra a própria concepção laica de Estado.

A presença do religioso no espaço público, no caso brasileiro, está intimamente ligada à própria história do país, de perfil multirreligioso, onde uma maioria esmagadora da população declara acreditar em Deus, de modo a encontrar força na crença para ter esperanças no futuro, apesar dos sofrimentos que presencia, com a corrupção na política e em outros setores da sociedade, com a violência urbana e rural, com a infância e a velhice abandonadas e outros quadros de injustiça social (SANTOS, 2015, p. 80).

Esquadrinhando os principais aspectos da religiosidade brasileira atual, chega-se a um mais preocupante, que pode ser resumido ao vocábulo "Fundamentalismo", no sentido de, 
exatamente, abranger uma série de condutas, pensamentos e construções dogmáticas abusivas, irrazoáveis e, na maioria das vezes, criminosas.

O termo "Fundamentalismo" teve suas raízes históricas definidas no Protestantismo europeu e norte-americano, na virada do século XIX para o XX, como um conjunto doutrinário de reações às proposições do liberalismo teológico no campo protestante e também a posições oficiais da Igreja Católica Romana no período do pontificado de Pio X (1903-1914), refratárias à emancipação da razão e a aspectos da cultura moderna (RIBEIRO, 2013, p. 65).

Porém, hoje a palavra "Fundamentalismo" é aplicada aos grupos religiosos das mais diversas religiões e culturas, para se referir a um posicionamento tido como conservador, tradicional e sectário, ou ainda para se referir àquele que, em nome de fé, atua na política de forma extremista ou radical (ORO, 2013, p. 70).

Ribeiro (2013, p. 66) afirma que pode ser classificado como Fundamentalismo "qualquer corrente, movimento, ou atitude, de cunho conservador e integrista, que enfatiza a obediência rigorosa e literal a um conjunto de princípios básicos, desprovidos de visão dialógica".

Essas posturas fundamentalistas são aquelas que expressam intolerância e desrespeito pela crença ou não crença alheia e, por extensão, afetam, efetiva ou potencialmente as liberdades de pensamento, expressão, reunião, associação, bem como a dignidade, a igualdade, a fraternidade e, num sentido mais amplo, comprometem todo o arcabouço democrático.

Essa anomalia, no campo da religiosidade, pode gerar posicionamentos e condutas extremadas, como ocorre quando alguém é visto como um fanático na vivência de sua fé, ou quando interpreta um texto sagrado de maneira absolutamente literal, situação essa que gera a esse indivíduo a pecha de "fundamentalista" (ORO, 2013, p. 69).

Ribeiro (2013, p. 66) afirma que pode ser classificado como Fundamentalismo "qualquer corrente, movimento, ou atitude, de cunho conservador e integrista, que enfatiza a obediência rigorosa e literal a um conjunto de princípios básicos, desprovidos de visão dialógica".

No Brasil, persistem os episódios de intolerância religiosa, testemunhados de diversos modos, como por ofensas físicas e morais, atitudes preconceituosas, tratamentos diferenciados 
em razão da crença, e outras ignomínias, pautadas em posturas fundamentalistas, que afetam religiões minoritárias, como as de matriz africana, e que requerem do Estado e da sociedade constante fiscalização e o aperfeiçoamento dos instrumentos de garantia à liberdade religiosa em nosso país.

\section{ALGUNS INFLUXOS HIPERMODERNOS SOBRE A RELIGIOSIDADE NO BRASIL}

A convivência em um mundo globalizado estabelece uma grande comunidade internacional de comportamentos, pensamento e decisões, especialmente na fração planetária compreendida como o Ocidente.

Nas palavras de Bauman (1999, p. 8), a “Globalização é o destino irremediável do mundo, um processo irreversível", e como tal corresponde a um processo que afeta a todos na mesma medida e da mesma maneira, de sorte que todos estão sendo "globalizados", ainda que isso não seja voluntário ou permitido individualmente.

Tais considerações são trazidas para demonstrar que, mesmo (e talvez, muito contundentemente) no campo das religiosidades, a internacionalização de alguns modus vivendi apontem para essa "nova ordem mundial", capaz de uniformizar ou, pelo menos, similarizar, determinados fenômenos religiosos.

Realizando uma leitura desse mundo globalizado, Gilles Lipovetsky e Sébastien Charles identificam uma fase subsequente à afamada pós-modernidade, denominada "hipermodernidade", situada, historiograficamente, a partir dos anos 80 , do século passado.

A eleição do prefixo "hiper" foi feita para realçar o conceito do "exagero", presente nas práticas das sociedades desse tempo, refletidas tanto nos aspectos institucionais e conceituais, como também individuais e subjetivos.

Escolher por fazer compras em um "hipermercado", ao invés de um pequeno comércio, por exemplo, denota essa preocupação pela maximização da busca da satisfação, das oportunidades e do prazer.

A partir daí, por esse mesmo prisma, vê-se que os comportamentos humanos, em geral, estariam, ainda que inconscientemente, associados aos excessos de consumo, modas, narcisismo, materialismo, hedonismo, emocionalismos, individualismo, utilitarismo e demais consequências dessa hipermodernidade.

Impossível se pensar que a religiosidade, no Brasil e em outras partes do mundo, estaria incólume aos "tempos hipermodernos", ainda que se tenha em conta a extrema 
variabilidade de tradições, denominações, liturgias, fazeres e saberes religiosos que integram o conjunto da religiosidade em nosso país e em outras partes do mundo, de modo que não é possível se imaginar que a "era do exagero" tenha se tornado uma tônica no exercício de todas as religiosidades.

Portanto, a se falar nos possíveis influxos hipermodernos sobre a religiosidade no Brasil, tem-se que, por justiça e razoabilidade, afirmar que esse perfil acaba sendo mais notada em determinadas porções dos adeptos e das instituições religiosas brasileiras, mas não verdadeiramente em todos.

Ainda assim, relevante que essa análise seja considerada, pois o caráter hipermoderno da religiosidade é significativamente notado, inclusive reconfigurando antigos hábitos religiosos e apresentando curiosas semelhanças no agir religioso entre grupos e pessoas, mesmo que de diferentes partes do mundo.

Conforme já exposto, o cenário religioso brasileiro é vasto, plural e sincrético, comportando ainda inúmeras práticas e propostas ecumênicas. Toda essa diversidade não permitiria que, em um breve estudo, houvesse espaço para a abordagem dos reflexos da hipermodernidade perante todas as religiões do Brasil, ainda que se tomassem por base estatística as mais incidentes, em termos de adeptos ou representatividade institucional no país.

Desse modo, faz-se aqui um recorte mais específico para a análise dos influxos hipermodernos sobre as comunidades religiosas protestantes brasileiras, especialmente aquelas denominadas pentecostais ${ }^{2}$ e neopentecostais ${ }^{3}$.

A partir das observações feitas por Lipovetsky e Charles, no que tange ao comportamento humano hipermoderno e que atinge também a seara da religiosidade, torna-se possível constatar que determinados traços da hipermodernidade estão presentes no fazer religioso de muitas dessas instituições pentecostais e neopentecostais brasileiras, assim como na conduta individualizada dos seus adeptos e líderes.

A aposta na performance dos líderes religiosos é uma constante, seja pela oratória, quanto pelos pretensos “poderes”, relacionados à cura, obtenção de melhoria das condições

\footnotetext{
${ }^{2}$ Integram o Protestantismo Pentecostal denominações como as assembléias de Deus, a Igreja do Evangelho Quadrangular, a Congregação Cristã no Brasil, Igreja de Nova Vida, Igreja Deus é Amor, dentre outras ${ }^{3}$ Integram o Protestantismo Neopentecostal denominações como Igreja Universal do Reino de Deus, Igreja Internacional da Graça de Deus, Igreja Renascer em Cristo, Igreja Mundial do Poder de Deus, dentre outras.
} 
financeiras e sucesso nos relacionamentos familiares e amorosos em favor dos fieis dessas igrejas.

A concepção da boa performance religiosa e da mentalidade de que "é só vitória", difundida durante os cultos e outras reuniões, presenciais ou virtuais, coincide com a ideia da hiperfuncionalidade e com aspectos de hedonismo e narcisimo, anunciados por Lipovetsky e Charles.

$\mathrm{Na}$ esteira da religiosidade contemporânea, marcada por religiões hedonistas, que alimentam em seus fiéis o perfil de "consumidores" de bênçãos, milagres, curas, conquistas materiais, fama, sucesso e outras formas de poder, a manipulação do sagrado por líderes religiosos inescrupulosos alimenta discursos fundamentalistas, que impõem verdades inquestionáveis, similares a “ditaduras da fé”, também nocivas ao ambiente democrático.

A "religiosidade do medo", isto é, a difusão de uma religião que fomenta o medo do castigo, o peso da culpa e do pecado, o temor a divindades impiedosas e outras formas de ameaça e coação, igualmente são antagônicas aos ideais de liberdade, solidariedade, igualdade e outros valores importantes para a democracia.

A expansão dessas instituições também faz parte de tais projetos religiosos, com a ampliação ou construção de novos templos, para comportar mais fieis, bem como outras propriedades ou espaço na programação de emissoras de televisão e rádio, gravadoras e editoras, canais e sítios na internet e ampla divulgação midiática, no sentido de permitir a hiperfuncionalidade da instituição e escalada mercadológica.

Outro influxo hipermoderno verificável nessas denominações diz respeito à lógica da moda e do consumo, conforme preconizam Lipovetsky e Charles, ao fazerem a leitura desse tempo.

Além do "modismo", que estabelece padrões comportamentais, como o modo de orar, de se vestir e como praticar o lazer, observam-se atitudes consumeiristas derivadas, como por exemplo, somente adquirir produções artísticas e culturais de religiosos perfilados com a doutrina dessas igrejas e adotar uma "aparência social" compatível, como o estilo da roupa a ser usada e as escolhas das programações televisivas ou turísticas.

No entanto, nesse aspecto da lógica de consumo, chama a atenção o perfil assumido por muitos desses religiosos, como verdadeiros "consumidores" do serviço oferecido por aquela igreja ou seu líder, o que pode descambar para uma relação negocial, utilitarista e 
materialista, provavelmente afastada de princípios e valores sustentados pelas religiões tradicionais.

Por fim, Lipovetsky e Charles comentam sobre uma religiosidade individualizada, paradoxalizada com os grandes ajuntamentos humanos, propostos e praticados por essas denominações religiosas comentadas.

$\mathrm{O}$ individualismo exacerbado de muitos desses religiosos, em termos de querer resguardar sua privacidade, almejar posições de destaque ainda que concorrendo com outros de seus "irmãos", fatores psicológicos referentes a desilusões ou desconfianças já sofridas em outras experiência religiosas, confronta-se com a proposta de tais igrejas, que prezam pela realização de assembléias numerosas, eventos com grande apelo midiático e demonstração de poderio institucional. No frigir dos ovos, poderia se pensar em "multidões de solitários".

\section{PANDEMIA, CONFINAMENTO E OS SEUS EFEITOS SOBRE A RELIGIOSIDADE BRASILEIRA}

A pandemia pelo novo Coronavírus, como já explanado por muitos, veio lançar luzes sobre diversas mazelas humanas e, em outras perspectivas, realçar os mais nobres sentimentos e atitudes humanas, especialmente no que se refere à solidariedade, empatia e alteridade.

Tem-se a percepção que a pandemia constitui um autêntico "divisor de águas", historicamente falando, mas também um mecanismo de decantação, capaz de separar a boa substância das impurezas que com ela estavam misturadas.

As incontáveis controvérsias relacionadas à pandemia e às suas consequências e dimensões, nas mais diversas perspectivas individuais e sociais, aguçaram ainda mais posições já polarizadas por outras questões ideológicas e políticas, e ainda parecem longe de se encerrarem.

A partir daí, um sem número de filósofos, cientistas, políticos, religiosos e tantas outras vozes se lançaram a fazer a leitura desse tempo pandêmico e pandemônico, seja para lançarem projeções sobre o "pós-pandemia", ou tão-somente para contribuírem com os seus contemporâneos para essa difícil travessia enfrentada pela humanidade.

No campo das religiões, naturalmente, os reflexos da pandemia se fizeram agudos, praticamente em todas as regiões do planeta, alterando liturgias, tradições, comunhões, 
eventos, e comportamentos em geral, dos líderes, adeptos e das próprias instituições e comunidades religiosas.

Por uma simples verificação diária das notícias do Brasil e do mundo, perfeitamente notório que a mudança dos hábitos religiosos se deu com ampla predominância em todas as sociedades humanas, desde os primeiros meses de 2020, não sendo possível, até a presente data, determinar-se quando e de que forma vão findar tais alterações.

No Brasil, especialmente até o término do primeiro semestre, muitas discussões foram travadas quanto à aplicação das restrições sanitárias ou não também para os ajuntamentos religiosos, notando-se uma tendência pela postura mais cautelosa, ou seja, pela não realização dos eventos religiosos coletivamente.

Chegou a ser veiculado pela imprensa que igrejas estariam desafiando recomendação de suspender missas e cultos diante da pandemia do Coronavírus, numa clara referência às religiosidades católica e pentecostal brasileiras (PIRES, 2020).

Travou-se, nesse momento, uma "batalha entre direitos fundamentais", pois de um lado estava o direito à saúde e a proteção à vida, e no outro extremo, o direito à liberdade religiosa, com o seu corolário, que abriga a liberdade de consciência e de culto.

No cotejamento de tal cenário com alguns aspectos acima mencionados, referentes aos influxos hipermodernos sobre determinadas denominações religiosas, como por exemplo, a ênfase nos ajuntamentos e na performance de seus líderes e sucesso de seus seguidores, tornase compreensível porque certos líderes religiosos manifestaram irresignação com as restrições à realização dos eventos religiosos.

Interessante ainda, por observação, que esse momento de controvérsia foi mais sentido exatamente no universo das igrejas que desenvolvem a religiosidade pautada na concepção do "hiper", anunciado por Lipovetsky e Charles e que investem suas fichas no retorno de audiência, público e arrecadação de dízimos e ofertas a partir da realização desses mesmos ajuntamentos.

Não se observou, ao menos na grande mídia brasileira, e como regra geral, notícias ou reclamações quanto à suspensão das reuniões religiosas de outras tradições e denominações religiosas, como as giras e sessões das religiões afro-brasileiras, como Candomblé e Umbanda.

Não se pode esquecer que está a se falar do mesmo direito fundamental, que é a liberdade religiosa, e de indivíduos e grupos que, não obstante suas opções religiosas serem 
diversas, merecem o mais absoluto e prudente tratamento isonômico, inclusive pela laicidade estatal, estabelecida pela Carta constitucional de 1988.

Todavia, é provável que o re ligare, enquanto conceito sociológico e teológico não tenha a mesma dimensão e efeitos, capazes de atender a todos os níveis de religiosidade. Isso porque pensar "religião" não é suficiente para estabelecer uma ideia homogênea de princípios, práticas e realidades.

Uma prova disso é uma classificação para as religiões em dois grandes blocos, as culturalistas e as prosélicas, onde o critério determinante para a distinção entre as duas categorias é o advento da conversão.

As religiões consideradas culturalistas são as que não possuem um gesto, um ritual, ou um momento específico que signifique, ou que represente a conversão. Nessas religiões, não há conversão, mas um encontro. A cultura é o elemento principal nessa relação entre adepto e religião. Estão nessa categoria o Candomblé, a Umbanda, as tradições ciganas e indígenas.

Já as religiões prosélicas são aquelas que comportam, na sua estrutura litúrgica, o ato de convencimento e o instante que marca a conversão. Muitas reconhecem o momento do batismo, da consagração, ou o dia em que o adepto aceitou formalmente o livro sagrado, ou fez um juramento (público ou íntimo), como marcos do ato da conversão. Enquadram-se nessa categoria o Catolicismo e o Protestantismo, em suas várias vertentes.

Conforme já informado, as reclamações mais eloquentes contra o "confinamento religioso" se deram a partir de manifestações de praticantes de religiões prosélicas no Brasil, donde se pode chegar a duas conclusões, diametralmente opostas, principalmente numa comparação com o "silêncio" dos religiosos culturalistas a esse respeito.

A primeira conclusão é que essa busca pelo ajuntamento tenha se dado por motivações eminentemente transcendentais, pois que é na comunhão que o instante da conversão pode se dar e, portanto, a realização das missas e cultos é fundamental para tal escopo.

Contudo, numa outra conclusão, inversamente tomada como interpretação, é de que tal pressão pelos ajuntamentos possa ter sido uma questão basicamente institucional e relacionada aos próprios interesses econômicos e mercadológicos dessas igrejas, interessadas em manter o seu poderio e sua ideologia triunfalista. 
Paradoxalmente, poderia se esperar das religiões culturalistas que essa queixa pela suspensão de suas reuniões religiosas fossa mais eloquente, tendo em vista que tais religiosidades não são fundadas em atos de conversão, mas sim nos encontros ritualísticos, durante os quais os adeptos trocam experiências de transcendência, como transes espirituais e ofertas às suas deidades e de imanência, como as vestimentas típicas, o uso de temperos e comidas e o uso de dialetos próprios.

Portanto, sejam quais forem as conclusões a serem consideradas, vê-se que o conceito de religião não parece atender a todas as possibilidades de religiosidades, assim como a pandemia e o confinamento repercutiram de modos bastante diferenciados em se tratando das religiões no Brasil.

\section{CONCLUSÃO}

$\mathrm{Na}$ conclusão do presente artigo, vê-se o quanto a pandemia pelo Coronavírus vem ressignificando conceitos, pensamentos e atitudes, além de evidenciar virtudes e defeitos, superações e derrotas.

A surpresa que a pandemia proporcionou à humanidade autenticou que boa parte das novas relações sociais são genuínas, independentemente de revelarem boas qualidades ou desvios de comportamento.

Assim, de um modo geral, aquele que era mesquinho e egoísta, provavelmente se tornou ainda mais desprezível, enquanto o indivíduo altruísta e empático teve e está tendo oportunidades de expressar sua alteridade. $\mathrm{O}$ mesmo se diga para as instituições.

As dúvidas e opiniões quanto ao enfrentamento do vírus e de seus sintomas e letalidade continuam ocupando os espaços de todas as mídias e círculos de conversas, assim como influenciando na tomada de decisões e estabelecimento de rotinas e protocolos, que vão desde os estabelecimentos hospitalares até as arenas esportivas e ambientes educacionais.

Obviamente, que as práticas religiosas não ficariam de fora de todas essas implicações, e acabaram por se tornar um interessante laboratório para a observação e análise de algumas condutas humanas, já que, nesses momentos, o perigo da doença e da morte coloca a fé e a razão, e a religião e a ciência em possíveis (mas não necessários) duelos. 
A proposta do artigo foi apresentar três frentes, relacionáveis entre si, ou seja, a religiosidade brasileira, os traços da hipermodernidade anunciados por Gilles Lipovetsky e Sébastien Charles e alguns efeitos da ocorrência da pandemia no ambiente da sociedade brasileira, onde os três mencionados parâmetros giraram em torno do mesmo eixo, que é o fenômeno religioso.

Pode-se demonstrar que a religiosidade brasileira, eclética, plural, sincrética e de vocação "democrática" é um traço peculiar de nosso povo, que deve ser preservado e protegido de determinadas tentativas nefastas de disseminação de intolerância e ódio, como aquelas que são fomentadas por grupos e indivíduos fundamentalistas.

Uma religiosidade que convive com "aproximações perigosas" entre o poder político e o poder religioso, como a emergência de partidos confessionais e o crescimento da influência de cunho religioso em decisões que cabem ao Estado, nos moldem de sua laicidade fixada pela Constituição brasileira de 1988.

Assim, manifestações feitas por ocupantes de cargos públicos, por exemplo, pautadas em suas pessoais convicções religiosas, que tenham por escopo definir políticas públicas ou julgar litígios, soam como verdadeiras ameaças à laicidade e representam, em última análise, violação à sadia liberdade religiosa.

Da mesma forma, a religiosidade brasileira é credora de uma constante e obstinada proteção jurídica e política diante de toda e qualquer conduta que represente perseguição, preconceito, violência ou qualquer tipo de atentado à liberdade de consciência e de culto, uma vez que a religião das minorias ainda vem sendo alvo de constantes ataques.

$\mathrm{Na}$ análise dos influxos hipermodernos sobre a religiosidade brasileira, viu-se que determinadas vertentes religiosas do Pentecostalismo e Neopentecostalismo encarnam alguns perfis apontados por Lipovetsky e Charles, como a lógica do consumo e da moda, a ênfase na performance religiosa, o triunfalismo, a massificação da publicidade do marketing e a valorização dos grandes ajuntamentos humanos.

Nesse particular, a questão das reuniões religiosas, nesses tempos de pandemia, foi questão central de muitos debates e controvérsias, principalmente nos primeiros meses da pandemia no Brasil, fato que ganhou mais repercussão entre as chamadas religiões prosélicas, dentre as quais figuram o Catolicismo e os diversos ramos do Protestantismo. 
Viu-se, no entanto, que as religiões chamadas culturalistas, como aquelas de matriz africana, indígena e cigana, mesmo com suas liturgias estruturadas nos rituais, não foram, como regra geral, cenário de reclamações contrárias às medidas de confinamento estabelecidas em determinadas ocasiões pelas autoridades políticas e sanitárias brasileiras.

Portanto, a religiosidade, de um modo geral, continua a ser um campo bastante complexo e que requer observações atentas e contextualizadas, mesmo em tempos de crise como estes vividos pela humanidade.

\section{REFERÊNCIAS}

BAUMAN, Zygmunt. Globalização: as conseqüências humanas. Tradução Marcus Penchel. Rio de Janeiro: Jorge Zahar Editor, 1999.

BRASIL. [Constituição (1988)]. Constituição da República Federativa do Brasil de 1988. Brasília, DF: Presidência da República, [2020]. Disponível em: http://www.planalto.gov.br/ccivil_03/constituicao/constituicao.htm. Acesso em: 20 set. 2020.

CHARLES, Sébastien; LIPOVETSKY, Gilles. Os tempos hipermodernos. Tradução Mário Vilela. São Paulo: Editora Barcarolla, 2004.

DA MATTA, Roberto. A casa e a rua: espaço, cidadania, mulher e morte no Brasil. Rio de Janeiro: Guanabara, 1987.

DAMATTA, Roberto. O que faz o Brasil, Brasil? Rio de Janeiro: Rocco, 1986.

GIUMBELLI, Emerson. A presença do religioso no espaço público: modalidades no Brasil. Revista Religião e Sociedade, v. 28, n. 2, 2008. Disponível em: https://www.scielo.br/scielo.php?pid=s0100-

$85872008000200005 \&$ script=sci_arttext. Acesso em: 20 set. 2020.

MAYEUR, Jean-Marie. Partidos Católicos e Democrático-Cristãos Europeus. In: BOBBIO, Norberto; MATTEUCCI, Nicola; PASQUINO, Gianfranco. Dicionário de política. Brasília: UNB, 1986.

ORO, Ivo Pedro. O fenômeno religioso: como entender. São Paulo: Paulinas, 2013.

PFEFFER, Raneto Somberg_A contribuição do sincretismo brasileiro para a construção de uma ética global. Revista Conjectura: Filosofia e Educação, Caxias do Sul-RS, v. 18, n. 2, p. 107-121, mai./ago. 2013. Disponível em: http://www.ucs.br/etc/revistas/index.php/conjectura/article/view/1510/pdf_134. Acesso em: 25 set. 2020.

PIRES, Breiller. Igrejas desafiam recomendação de suspender missas e cultos diantes da pandemia do coronavírus. El País, Brasil. São Paulo, 19 mar. 2020. Disponível em: https://brasil.elpais.com/brasil/2020-0320/igrejas-desafiam-recomendacao-de-suspender-missas-e-cultos-diante-da-pandemia-do-coronavirus.html. Acesso em: 25 set. 2020.

RIBEIRO, Cláudio de Oliveira. Um olhar sobre o atual cenário religioso brasileiro: possibilidades e limitares para o pluralismo. Estudos da Religião, São Paulo-SP, v. 27, n. 2, p. 53-71, jul./dez. 2013. Disponível em: https://www.metodista.br/revistas/revistas-ims/index.php/ER/article/view/4434/3768. Acesso em: Acesso em: 25 set. 2020.

SANTOS, Alberto Pereira dos. Geopolítica das igrejas e anarquia religiosa no Brasil: por uma geoética. Rio de Janeiro: Gramma, 2015. 